\title{
Marronnages érotiques : le dancehall jamaïcain entre culture et slackness
}

Entretien avec Carolyn Cooper

Erotic Marronage: Jamaican Dancehall, between Culture and Slackness. An

Interview with Carolyn Cooper

Jérôme Beauchez et Carolyn Cooper

\section{(2) OpenEdition}

\section{Journals}

\section{Édition électronique}

URL : http://journals.openedition.org/conflits/19414

DOI : $10.4000 /$ conflits. 19414

ISSN : $1777-5345$

Éditeur :

CCLS - Centre d'études sur les conflits lilberté et sécurité, L'Harmattan

\section{Édition imprimée}

Date de publication : 20 décembre 2016

Pagination : 189-206

ISBN : 978-2-343-11087-5

ISSN : 1157-996X

\section{Référence électronique}

Jérôme Beauchez et Carolyn Cooper, «Marronnages érotiques : le dancehall jamaïcain entre culture et slackness », Cultures \& Conflits [En ligne], 103-104 | automne/hiver 2016, mis en ligne le 20 décembre 2016, consulté le 30 mars 2021. URL : http://journals.openedition.org/conflits/19414 ; DOI : https:// doi.org/10.4000/conflits. 19414 


\title{
Marronnages érotiques : le dancehall jamaïcain entre culture et slackness
}

\author{
Entretien avec Carolyn Cooper 1
}

\section{Jérôme BEAUCHEZ}

Jérôme Beauchez est sociologue, maître de conférences à l'université de Lyon/Saint-Etienne, chercheur au Centre Max Weber et membre du LabEx "Intelligences des Mondes Urbains". Actuellement en délégation CNRS auprès de l'Institut interdisciplinaire de recherche sur les enjeux sociaux (IRIS), il coordonne le programme ANR Socioresist. Dans ce cadre, Jérôme Beauchez mène des enquêtes ethnographiques auprès de différentes populations marginalisées dont il s'agit d'interroger les résistances quotidiennes à l'adversité des dominations de "genre ", de "classe » ou de "race ". Dernière publications: "'Chaos in France': Fieldnotes from the French Punk Experience », Cultural Dynamics (à paraitre en décembre 2016); avec Pierre Lauret, " "Ôter leurs majuscules aux concepts" : ethnographie d'un sport de combat. Entretien avec Jérôme Beauchez ", Cahiers philosophiques, $n^{\circ} 146,2016$, pp. 83-119.

Drofesseure de littérature et d'études culturelles à l'Université des West 1 Indies en Jamaïque, Carolyn Cooper peut à maints égards être décrite comme une instigatrice des recherches sur le dancehall; un espace musical ô combien décrié, mais dont la popularité ne se dément pas dans l'ensemble des Antilles - voire bien au-delà. Sorte de cousin caribéen du rap américain, le dancehall est souvent présenté comme l'enfant terrible du reggae, auquel il aurait succédé au cours des années 1980 pour finir par occuper le devant de la scène musicale jamaïcaine ${ }^{2}$. À l'instar du rap, c'est d'abord une musique qui

1. Réalisé le lundi 13 juillet 2015 à Fort-de-France dans le cadre d'une recherche sur les expressions artistiques de l'Atlantique noir menée au sein du programme ANR Socioresist. $N b$ : Lorsqu'elles sont signalées par un astérisque, les références musicales et filmiques citées au fil du dossier peuvent être consultées par le biais d'une liste YouTube créée à cet effet et accessible via le lien suivant : https://www.youtube.com/playlist?list=PLbCt_9Yhu8O9AHUAmk0D6mDHIayjeqbi. L'ensemble a été regroupé à partir de matériaux déjà diffusés par les internautes; toutes les fois que cela a été possible, les documents présentant des sous-titres en français ont été privilégiés.

2. Sur cette acception du dancehall, voir : Katz D., Solid Foundation. An Oral History of Reggae, New York, Bloomsbury, 2003, pp. 329-348; voir également, traduit en français : 
porte l'expérience de la pauvreté ; elle résonne comme l'écho de la dureté des conditions de vie dans les ghettos de Kingston. Ainsi le dancehall fait-il souvent scandale auprès de la «bonne société », tant par ses mises en scène du sexe, de la violence et de l'argent - autant de sujets qui renvoient au domaine du slackness (i.e. de la débauche) - que par les frasques de ses acteurs dont une partie fait régulièrement les gros titres des quotidiens. Pourtant Carolyn Cooper voit plus loin. Débutés dans les années 1990, ses travaux sur le sujet montrent que le dancehall s'enchâsse profondément dans la trame des cultures populaires jamaïcaines, dont il fait entendre nombre de conflits ; une propension à la critique sociale que ses artistes rangent précisément sous la bannière de leur culture (celle du peuple des ghettos). L'un des principaux arguments développés par l'auteure consiste dès lors à plaider pour une compréhension du phénomène qui ne se contente pas d'opposer, mais cherche plutôt à articuler culture et slackness comme les deux faces d'une même pièce où se joue - par la rupture des codes de la bienséance (le slackness) ou la critique sociale explicite (la culture) - un même élan de résistance affiché par les plus pauvres à l'égard de la société bourgeoise dont ils éprouvent le rejet tout comme la domination. C'est donc de ce regard à l'entre-deux dont il sera question tandis que nous évoluerons au rythme du dancehall. Afin qu'il puisse être pleinement entendu, les lignes qui suivent composeront une brève introduction à l'ethnohistoire de ce style musical dont l'analyse contemporaine sera ensuite assurée par l'une des meilleures spécialistes du genre ${ }^{3}$.

\section{Des bruits dans le sang, ou comment la rue jamaïcaine résonne...}

D'un point de vue formel, le dancehall moderne se compose de rythmiques le plus souvent digitales - les riddims, selon leur appellation jamaïcaine - amplifiant les syncopes du couple basse-batterie, lesquelles servent d'appui à la scansion des rimes qu'élancent les deejays. Le terme désigne en Jamaïque celles et ceux qui - tels les M.C. (Masters of Ceremony) du rap américain - ne parlent pas plus qu'ils ne chantent sur la musique. Ces performeurs de l'oralité déclament plutôt leurs textes, et chevauchent les rythmes en jouant de la musicalité d'un phrasé qui participe du sens qu'ils déploient autant que les mots qu'ils emploient. Leur premier lieu de formation et leur habitat naturel, si l'on peut dire, est le sound system : un système de sonorisation dont les colonnes d'enceintes, généralement disposées en plein air, permettent de jouer de la musique amplifiée ; c'est-à-dire les fameux riddims choisis par un selec-

Bradley L., Bass Culture. Quand le reggae était roi, Paris, Éditions Allia, 2005 [2000], pp. 573-617.

3. Outre les remerciements que l'auteur de ces lignes adresse à Carolyn Cooper pour sa grande disponibilité, il tient également à signaler sa dette vis-à-vis du travail de Denis-Constant Martin. Auteur en 1982 d'un ouvrage fondateur des recherches françaises sur la musique jamaïcaine contemporaine - Aux sources du reggae, Roquevaire, Éditions Parenthèses -, ce chercheur est une véritable inspiration pour toutes celles et ceux qui s'efforcent de prolonger son intérêt pour ces OPNI (objets politiques non identifiés) que sont les musiques populaires de l'Atlantique noir ou d'ailleurs. 
ter, qui officie aux platines en tant que responsable de la sélection musicale sur laquelle le talent vocal des deejays est appelé à s'exprimer.

Si l'on voulait densifier la description d'un tel art expressif, il faudrait ajouter qu'il est plus ancien que le dancehall actuel ne le laisse supposer. Car les premiers sound systems se sont établis dans les rues de Kingston dès les années 1950 4. Ils participaient alors d'une stratégie commerciale visant à animer le passage devant les boutiques désireuses d'attirer le chaland. Tom "The Great Sebastian" Wong, considéré comme un pionnier en la matière, a ainsi modestement débuté par l'animation des abords de sa quincaillerie, dont l'entrée résonnait des dernières productions du rhythm'n'blues en provenance des États-Unis ; prenant la mesure du potentiel commercial de cette activité musicale, il s'est alors lancé dans l'organisation de soirées qui ont élu domicile sur de grandes pelouses - les lawns - où lui et ses concurrents ont transporté leurs discothèques mobiles, de plus en plus nombreuses au fil de la décennie. Un marché concurrentiel du dancehall était en passe de se structurer. Au cours des années 1960, il allait être dominé par les Big Three (les trois grands) - i.e. Clement "Sir Coxsone" Dodd et son Downbeat Sound System, Arthur "Duke" Reid propriétaire du Trojan Sound et Vincent "King” Edwards qui possédait le Giant Sound System. Tandis que la compétition sonore faisait rage, la qualité de la sélection musicale de même que l'inventivité des animateurs de soirée - les deejays - ont très vite constitué autant d'arguments décisifs dans la conquête des publics. Ainsi Count Machuki (Winston Cooper)*, King Stitt (Winston Sparkes)*, Sir Lord Comic (Percival Wauchope)* et bien d'autres à leur suite, se sont-ils emparés des micros pour lancer en rimes et en rythme les morceaux qui faisaient danser les foules. Bientôt leurs interventions ne se sont plus limitées aux seules introductions des titres pour s'étendre à toutes les parties instrumentales (les versions) qu'ils ont conquises comme leur espace d'expression ${ }^{5}$. Tandis que le public attendait leurs exubérances verbales au moins autant que les morceaux qui leur servaient d'appui, ces hommes ont posé les fondations d'un nouvel art expressif indissociablement vocal et musical : le deejaying, ou toasting - puisqu'ils portaient littéralement un toast à la musique en la magnifiant par leurs rimes.

Quant aux propriétaires de sound systems qui employaient ces deejays, ils ont également ouvert des studios d'enregistrement. Ceux-ci - à l'instar du Studio 1 de Coxsone Dodd - ont permis de graver dans le vinyle les premiers actes d'une musique populaire jamaïcaine dont l'essor a rythmé l'accès de l'île à l'indépendance, acquise à l'égard de l'Angleterre en 1962 6. Le ska*" consti-

4. À ce sujet, voir l'essai d'historiographie proposé par l'anthropologue Norman Stolzoff dans son ouvrage Wake the Town and Tell the People. Dancehall Culture in Jamaica, Durham \& Londres, Duke University Press, 2000, pp. 41-64.

5. À ce propos, voir : Vendryes T., "Des versions aux riddims. Comment la reprise est devenue le principe de création musicale en Jamaïque (1967-1985) », Volume!, vol. 7, n 1, 2010, pp. 191-222. 
tuait alors la bande son des ghettos de Kingston. Né de l'inventivité d'un petit groupe de musiciens - les Skatalites - qui ont réalisé un syncrétisme musical composé de rythm'n'blues, de mento (une sorte de variante locale du calypso) et de jazz, le ska a très vite imposé sa rythmique répétitive sur laquelle de jeunes chanteurs n'ont pas tardé à s'essayer. Parmi eux se trouvaient quelques adolescents et futures stars internationales comme Bob Marley, Peter Tosh (membres du trio The Wailing Wailers*) ou Jimmy Cliff*. Au fil de la décennie, le tempo effréné du ska est devenu à la fois plus lent et langoureux, donnant naissance au rocksteady - lequel faisait la part belle aux trios vocaux et à leurs ritournelles* - puis au reggae* 7 . Ce dernier n'a pas tardé à s'affirmer comme la musique jamaïcaine emblématique du tournant des années 1970 ; une période qui a également été celle de son succès mondial, tandis que les scansions rythmiques du reggae s'alliaient aux percussions ainsi qu'aux thématiques du rastafarisme.

Présent en Jamaïque dès les années 1930, ce mouvement spirituel afro-centriste tire son nom du dernier empereur d'Ethiopie - le Ras Tafari, Haïlé Sélassié - dans lequel les rastas voient un messie et la figure du Christ noir réincarné. À l'instar du peuple juif dont l'exode est rapporté par la Bible, les rastas estiment que depuis l'esclavage ils vivent en déportation dans la nouvelle Babylone coloniale dont ils combattent toutes les institutions - politiques, religieuses ou scolaires - perçues comme vectrices de l'esclavagisme mental dans lequel l'homme noir serait maintenu. Le salut de ce dernier se trouverait dès lors dans l'idée de repatriation*, à savoir le retour sur la terre ancestrale d'Afrique (équivalent du royaume de Sion, ou Zion). En attendant la possibilité d'un tel retour, l'idée est de s'en remettre à Jah (le nom hébreu de Dieu) afin de résister au système babylonien dont il s'agit de déconstruire tous les mécanismes d'oppression qui ont éloigné les Noirs déportés de leur moi profond $(\text { far } I)^{8}$.

Dans les années 1970, alors que reggae et rastafarisme font cause commune contre l'oppression occidentale, ils deviennent (paradoxalement ?) des références de la contre-culture en Occident. L’allure et le style de vie des rastas - notamment leurs dreadlocks (littéralement des « nattes effrayantes » composées de longues nodosités capillaires) et leur usage de la ganja (mari-

6. Concernant le rôle de ces studios d'enregistrement dans la naissance puis l'établissement d'un " son jamaïcain », voir : Hitchins R., Vibe Merchants : The Sound Creators of Jamaican Popular Music, Londres \& New York, Routledge, 2016 [2014], pp. 73-96.

7. Sur ces changements stylistiques dans l'expression musicale jamaïcaine, voir : Chang K. et Chen W., Reggae Routes. The Story of Jamaican Music, Philadelphia, Temple University Press, 1998, pp. 30-52. En 2003, le français Pierre Simonin a publié un documentaire de cinquante-deux minutes intitulé Portraits de la musique jamaïcaine*, lequel part sur les traces des pionniers qui ont été à l'instigation de ces diverses sonorités caractéristiques de la richesse comme de l'identité musicale de l'île.

8. Sur tous ces points, voir notamment The Rastafarians (Boston, Beacon Press, 1997 [1988]), l'ouvrage de référence rédigé par l'anthropologue jamaïcain Leonard Barrett. 
juana) - en font des effigies rébellionnaires auprès de toute une jeunesse blanche inspirée par la musique de Bob Marley et quelques films en vogue sur les écrans européens 9 . En Jamaïque, ce sont les deejays - tels U Roy (Ewart Beckford)*, Big Youth (Manley Buchanan)*, Prince Far I (Michael Williams)* ou Trinity (Wade Brammer)* - qui propagent leurs dread talks (le langage rasta, souvent composé d'ellipses et de double sens ${ }^{10}$ ) dans les sound systems et sur les vinyles qui diffusent leurs scansions

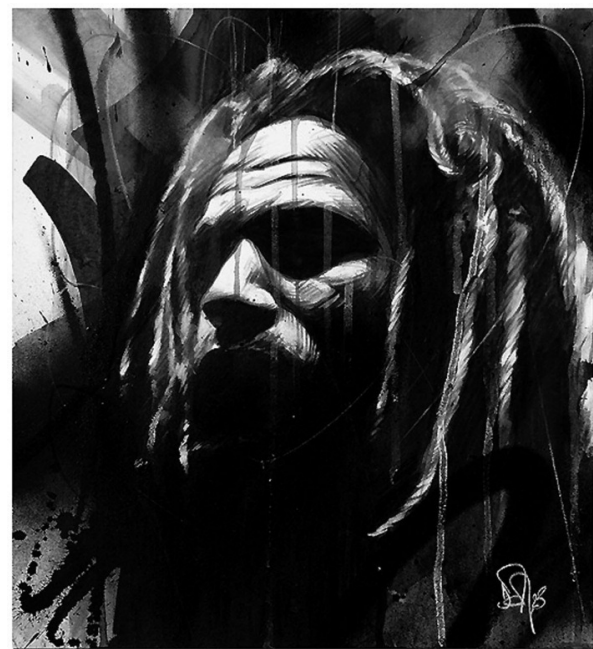

Soul Rebel, 2011 C Dan23 vocales au-delà des frontières de l'île. Si Rastafari devient ainsi le synonyme d'une spiritualité et d'une culture populaire consciente d'elle-même, des conflits et de l'oppression que vivent les Noirs les plus pauvres, les thématiques légères et relâchées ne disparaissent pas pour autant des dancehalls. Car on y vient également pour oublier la pénibilité des semaines de travail - voire son absence -, chassée l'espace d'un moment par les rythmes tonitruants du reggae. Ces deux aspects de la musique populaire jamaïcaine - conscience et relâchement, ou culture et slackness dans le vocabulaire du dancehall contemporain - structurent aujourd'hui encore une grande part de la production musicale de l'île. Au cours des décennies 1980 et 1990, la tendance au slackness s'est d'ailleurs faite de plus en plus explicitement sexuelle, tandis que le dancehall reflétait un nouveau durcissement des conditions de vie dans les ghettos où les armes à feu, la drogue et la violence n'ont cessé de proliférer. Une fois encore, la musique jamaïcaine et ses sound systems se sont faits l'écho de la rue et d'une nouvelle génération de deejays dont les rimes ont résonné de toutes ces turpitudes, ces envies ou ces espoirs déçus.

Or c'est précisément à l'entame de la décennie 1990 que Carolyn Cooper a publié son premier livre - Noises in the Blood [Des bruits dans le sang] ${ }^{11}-$, dont un chapitre traite du dancehall replacé dans la continuité historique d'une oraliture où la langue jamaïcaine prend littéralement corps au travers de

9. Ainsi par exemple de Rockers* (Kingston, Rockers Film Corporation, 1978) réalisé par le cinéaste helléno-américain Ted Bafaloukos, lequel a employé nombre d'entre les principaux acteurs de la scène reggae qui jouent leur propre rôle dans ce film-chronique du quotidien des ghettos jamaïcains, de leur violence et de l'espoir suscité par la musique mêlée au culte rasta.

10. Voir : Pollard V., Dread Talk. The Language of Rastafari, Kingston, Canoe Press University of the West Indies, 2000 [1994].

11. Cooper C., Noises in the Blood. Orality, Gender and the "Vulgar" Body of Jamaican Popular Culture, Oxford, Macmillan, 1993. 
la culture et de la geste populaire qu'animent celles et ceux qui la vivent au quotidien. Écrivains des proverbes et traditions du peuple, auteurs ou acteurs d'un théâtre où l'on s'exprime non pas en anglais littéraire mais en créole jamaïcain, activistes du reggae et - last but not least - danseuses, danseurs et deejays de la scène dancehall : Carolyn Cooper voit là autant de performeurs des arts expressifs qui tissent la trame d'une culture populaire dont l'un des piliers est la résistance qu'elle oppose aux institutions (post)coloniales. Non pas que cette résistance soit cherchée a priori. Mais sa langue et ses rythmes en provenance des rues vibrent plutôt dans le poignet de l'auteure, et résonnent ainsi jusque dans son écriture. Aussi a-t-elle consacré toute une série de textes au dancehall, dont elle propose une lecture des corps dansés qu'elle assimile à une forme de « marronnage érotique »; comprenez une érotisation des corps - et notamment celui des femmes - qui entre ouvertement en résistance (d'où l'idée de marronnage) vis-à-vis des codes bourgeois de la décence ${ }^{12}$. Si elle se réclame d'un féminisme noir en rupture avec les traditionnelles diatribes sur la sexualisation à outrance du corps féminin dans les performances dansées, une telle interprétation ne laisse pas de susciter les plus vives critiques en Jamaïque et ailleurs. Mais sur ces sujets, comme sur celui de l'homophobie dans le dancehall et la culture populaire jamaïcaine en général, Carolyn Cooper ne craint pas la polémique; plus que sa propre voix, c'est celle des deejays qu'elle tente de faire entendre sans que leurs mots ne soient sortis du contexte jamaïcain qui leur confère leur sens, et sans avoir nécessairement à choisir entre « bien » et «mal », ou « bon » et « mauvais »...

$* * *$

-Jérôme Beauchez (J.B.) : Pourriez-vous nous expliquer ce que les Jamaïcains entendent par «dancehall » et la différence qu'ils font entre slackness et culture?

-Carolyn Cooper (C.C.) : Le dancehall est la dernière version de la musique populaire jamaïcaine : des rythmes accélérés et une tendance générale aux thématiques de la sexualité, mais aussi de la violence - beaucoup de violence et d'armes à feu ! Vous pouvez entendre des morceaux où il est question d'arracher la moelle osseuse des gens, pour ne citer qu'un exemple... Tout semble d'ailleurs se passer comme si l'exacerbation de la violence dans le dancehall consistait en une tentative pour transcender la violence sociale par le

12. Ibid., p. 161. Voir également Soundclash: Jamaican Dancehall Culture at Large (New York, Palgrave Macmillan, 2004) - la principale publication de Carolyn Cooper sur le sujet - et, plus récemment, l'ouvrage collectif qu'elle a dirigé à propos de l'internationalisation de la musique populaire jamaïcaine sous le titre Global Reggae (Kingston, Canoe Press, 2012). Quant à la traduction française de ses travaux, à ma connaissance elle se limite au texte « Du reggae au ragga : que reste-t-il de la contestation ? ", paru dans un ouvrage collectif qu'a dirigé Alain Darré sous le titre Musique et politique. Les répertoires de l'identité (Rennes, PUR, 1996). L'ouvrage comme le texte en question sont disponibles en ligne : http://books.openedition.org/pur/24557?lang=fr 
biais d'une sorte de catharsis. Je sais que ce genre d'analyse n'est pas apprécié de tout le monde. Les gens croient parfois que j'excuse la violence verbale des deejays. Or il n'est pas question de ça. Mais si les Grecs ont pu opérer leur catharsis au travers du théâtre classique, alors pourquoi les Jamaïcains ne pourraient-ils pas le faire dans le dancehall, puisqu'il s'agit là aussi de faire face à la violence et à ses affects en les transposant sur une scène artistique ? En tout cas, c'est une lecture possible 13 !

Dans le dancehall, vous avez donc le slackness qui représente tout ce qu'il y a de plus irrespectueux : le sexe, la violence et tous ces comportements antisociaux que l'on associe au crime. Je présume que quelqu'un comme Vybz Kartel constitue l'exemple classique d'un parolier brillant, capable d'écrire sur tous ces sujets à la fois : le slackness aussi bien que la culture dont la conscience - c'est-à-dire la réflexion sur soi et tout un ensemble de problèmes sociaux apparaît précisément comme l'opposé du slackness... Dans les colonnes du Gleaner [avec le Jamaica Observer, l'un des deux grands quotidiens de la presse écrite], il m'est arrivé de tracer des parallèles entre Bob Marley et Vybz Kartel pour ce qui concerne l'écriture dite « consciente ». Pourtant, et en dépit de tous ses talents, Vybz Kartel n'a pas été en mesure de trouver sa place dans la société ; de sorte qu'il a fini en prison. Du point de vue de certains Jamaïcains, il incarne la quintessence de tout ce qui est mauvais dans le dancehall!

\section{Gaza made in Jamaica}

Adidja Palmer - plus connu sous le nom de Vybz Kartel - est né en 1976 et a grandi dans le ghetto de Portmore, à l'Ouest de Kingston. Fréquentant dès l'enfance les sound systems de son quartier, il s'y taille rapidement une réputation de ciseleur de rimes cadencées au rythme d'un environnement dont il éprouve chaque jour la dureté. Ses rues poussiéreuses jalonnées de baraques en tôle et de maisonnettes en fibrociment révèlent le dénuement, mais aussi la condition des sufferers - les pauvres - condamnés à vivre, ou plutôt à souffrir dans ce "Gaza " made in Jamaica. C'est en tout cas ainsi que $\mathrm{Vybz}$ Kartel a renommé son quartier, et baptisé sa garnison de fidèles - le " Gaza crew » - en allusion directe à la situation des Palestiniens opprimés par un gouvernement israélien qui les a, eux aussi, parqués dans leurs territoires et confinés au mépris; une situation que le deejay décrivait déjà en 2005 dans un morceau intitulé "Emergency »*. Cette conscience de l'oppression vécue par les siens ne l'a pourtant pas empêché d'en perpétuer la brutalité au travers d'un système entrepreneurial basé sur l'exploitation du ghetto comme étendard et comme marque. Un rhum estampillé au nom de Vybz Kartel, un cake soap (i.e. un savon conçu pour blanchir la peau) et un night-club ouvert à Kingston se sont ainsi ajoutés à d'innombrables odes au sexe et à la violence dont certains effets, loin d'être seulement cathartiques, ont vraisemblablement conduit au meurtre*. Tout du moins celui de Clive "Lizard" Williams, un ancien associé de Kartel que lui et ses

13. Pour une approche similaire, voir : Gaye A., «De l'espace dancehall comme refuge cathartique à la Jamaïque », Espaces et Sociétés, n 144-145, 2011, pp. 105-119. 
complices sont accusés d'avoir battu à mort avant de faire disparaitre son corps.

Prononcée en 2011, une première inculpation a lancé un véritable feuilleton judiciaire soldé en 2014 par la condamnation d'Adidja Palmer à trentecinq ans de prison. Les médias locaux ont estimé qu'au moment de son arrestation ses revenus atteignaient la somme mensuelle de dix millions de dollars jamaïcains (environ soixante-sept mille euros) 14. Loin d'avoir entamé sa notoriété, l'incarcération de Vybz Kartel est perçue par ses thuriféraires comme un combat de plus livré par l'« empereur de Gaza » contre I'appareil d'État. Quant à ses nombreux adversaires - y compris dans les ghettos -, ils voient plutôt en lui une sorte de " clown blanc » outrageusement tatoué et pratiquant le bleaching (i.e. l'éclaircissement de l'épiderme par l'application de produits dépigmentants) comme un reniement de soi ainsi que de tous les idéaux d'une fierté noire prônée par les rastas et leurs deejays " conscients »- dont les figures les plus populaires sont sans doute incarnées par Capleton (Clifton Bailey)* ou Sizzla Kalonji (Miguel Collins)*. Ô combien clivantes et clivées, la personnalité comme la musique de Vybz Kartel ne sauraient pourtant être rangées d'un seul côté d'une frontière qui isolerait hermétiquement le slackness de la culture. En 2012, le deejay s'est d'ailleurs piqué de livrer son analyse culturelle de la société jamaïcaine et de la pauvreté qui la gangrène dans un ouvrage qu'il a choisi d'intituler The Voice of the Jamaican Ghetto ${ }^{15}$. Sur la première de couverture, on peut lire : "Je prie pour que ce livre aide à changer la Jamaïque pour toujours $» . .$.

Mais si Vybz Kartel peut représenter le pire visage du dancehall aux yeux d'une majorité de gens, il faut ajouter que l'autre versant, celui de la culture, présente lui aussi une face que l'on oublie très souvent. Dans notre musique, l'aspect culturel est internationalement représenté par toutes ces compositions associées à Bob Marley et, dans une certaine mesure, à Peter Tosh ainsi qu'à tous les grands du reggae qui ont chanté contre l'injustice, tandis qu'ils paraissaient suivre un agenda politique clairement universaliste ; c'était une sorte de programme humaniste, si vous préférez, autour duquel toutes sortes de gens pouvaient se rassembler. Mais dans le même temps, et alors qu'on a fini par ériger ces artistes au rang d'icônes culturelles, les gens ont semblé omettre un élément central de cette culture qui n'est autre que l'engagement contre le colonialisme, les nouvelles formes d'impérialisme et toutes ces choses qui, en Jamaïque, sont précisément perçues comme relevant de la « haute culture ». De telle sorte que le reggae a d'abord constitué un langage de résistance contre certains systèmes élitistes dans notre pays. Et ce sont ces mêmes élites jamaïcaines qui voudraient aujourd'hui faire passer le reggae pour de la « haute culture » et ravaler le dancehall au rang du slackness! Ils font mine de ne pas se

14. Personnage récurrent de la vie médiatique, Vybz Kartel a fait l'objet de toute une série d'articles publiés tant dans le Gleaner que le Jamaica Observer. Pour ce dernier, Patrick Helber s'est livré à un travail d'analyse des caricatures qui ont représenté le deejay avant, puis au moment de son inculpation pour meurtre ; voir : Helber P., «"Ah My Brownin’ Dat!”: A Visual Discourse Analysis of the Performance of Vybz Kartel's Masculinity in the Cartoons of the "Jamaica Observer" ", Caribbean Quarterly, vol. 58, n 2-3, 2012, pp. 116-128.

15. Palmer A., Dawson M., The Voice of the Jamaican Ghetto: Incarcerated but not Silenced, Kingston, Ghetto People Publishing Company, 2012. 
rendre compte de la contradiction. Ils veulent plutôt voir le reggae comme cette grande chose qui s'est produite, et le dancehall comme cet affreux petit rejeton qui en est sorti! Quant à moi, je m'efforce de montrer que les choses sont un peu plus complexes. Par exemple - et c'est ce que je fais remarquer dans un chapitre de mon livre Soundclash -, lorsque Bob Marley fait usage du «feu » ses paroles sont entendues comme une métaphore biblique qui renvoie à l'idée du jugement. Mais lorsque Capleton en fait usage à son tour, il est perçu comme un incendiaire au sens propre du terme 16 ! Vous comprenez ? Les gens ne voient pas le même feu révolutionnaire dans le dancehall et dans le reggae!

\section{-J.B. : Comment décririez-} vous la place des femmes dans le dancehall, où elles semblent à première vue entièrement dominées par les hommes et soumises à leurs désirs?

-C.C. : Le dancehall constitue en effet un espace d'hégémonie masculine, de violence et de pénis symboliques représentés par les armes à feu ! Vous savez, il y a de cela un moment Shabba Ranks* parlait déjà de cette connexion métaphorique entre le pénis et le flingue ${ }^{17}$. Donc oui, la société jamaïcaine apparaît comme très patriarcale. Mais le fait que les femmes y assument souvent toute l'économie domestique ne signifie pas pour autant qu'elles sont

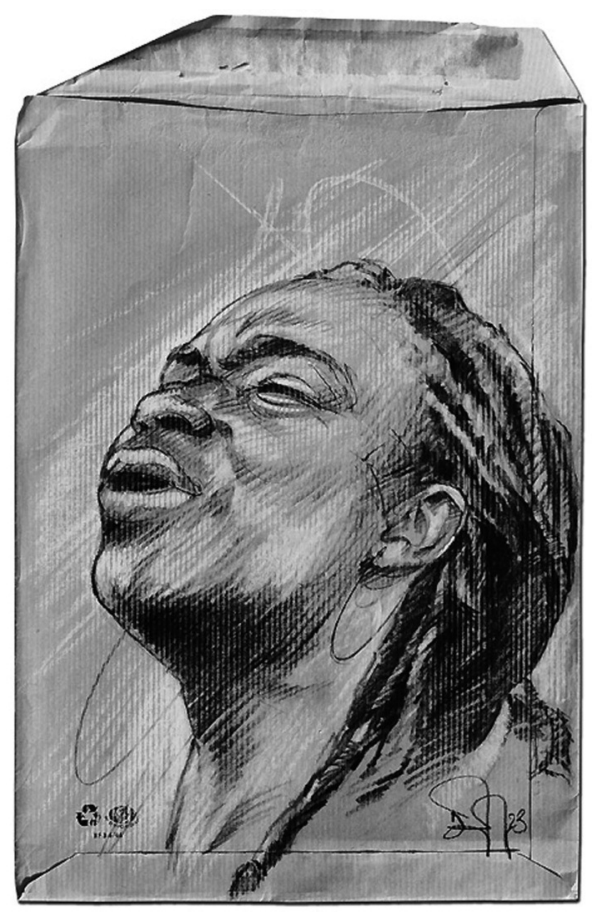

Magic Music, 2013 @ Dan23 dénuées de pouvoir. Ce que ça signifie est plutôt que les hommes censés s'occuper de leurs enfants demeurent souvent absents. Donc les femmes ont été forcées d'endosser un double fardeau : le leur et celui des hommes... Cela dit, tous ne sont pas délinquants! En vous arrêtant uniquement au dancehall, vous obtiendriez une représentation aussi négative que tronquée de la masculinité dans la culture jamaïcaine. Le dancehall ne vous révèle pas l'entière vérité ; c'est l'expression musicale

16. «"More Fire”: Chanting Down Babylon From Bob Marley to Capleton », Soundclash, op. cit., pp. 179-206.

17. Rexton Gordon, a.k.a Shabba Ranks, fut l'un des deejays les plus populaires des années 1990 au cours desquelles il a atteint une renommée internationale et fait maintes fois scandale pour la crudité de ses propos. Au sujet des armes à feu et des métaphores qu'il a forgées à partir d'elles, voir : Cooper, C., "Lyrical Gun: Metaphor and Role-Play in Dancehall Culture », Soundclash, op. cit., p. 154-157. 
d'une théâtralité où l'on joue des rôles : celui du badman [le voyou] en est un! Mais il véhicule bel et bien tout un ensemble de représentations selon lesquelles les hommes doivent gagner des choses, être en responsabilité au sens du leader, vous comprenez ${ }^{18}$ ?

Ceci dit, il ne faudrait pas oublier l'affirmation des femmes deejays sur la scène dancehall au cours des vingt-cinq dernières années. Quelqu'un comme Tanya Stephens, une chanteuse et une deejay tout à fait brillante, remet en cause un grand nombre de ces stéréotypes masculins dont nous venons de parler. Dans un morceau comme «Big Ninja Bike » (1998)*, elle chante qu'elle est d'une nature sensuelle, qu'elle recherche la satisfaction sexuelle et qu'elle ne veut pas d'un homme qui n'a jamais que des mots à la bouche et ne serait pas capable de lui offrir une bonne virée [a good ride]! Dans le même temps que les hommes vantent leur grande puissance sexuelle, vous avez donc des femmes - on pourrait également citer Lady Saw ${ }^{19}$ - qui les tournent en dérision et leur répondent : «Oh, tout ça c'est du baratin ! Montre-moi plutôt ce que tu sais faire au lieu de causer ! » Il y a beaucoup de mise en scène [bype] de la part des hommes dans le dancehall, et les femmes sont venues les contester sur ce qu'ils croyaient être leur domaine de prédilection...

Alors oui, peut-être qu'au premier regard les femmes dans le dancehall peuvent apparaître comme dénuées de pouvoir. Et une fois encore, on entend la vieille rengaine sur la façon dont les corps féminins sont exposés dans les vidéos et ainsi de suite... Moi je vois plutôt beaucoup de prise de pouvoir [empowerment], tant dans le verbe des femmes deejays qu'au niveau des représentations que les danseuses donnent d'elles-mêmes dans le public. Leurs corps suggèrent un sens de la fierté noire; il y a même beaucoup de fierté dans ces corps! Elles savent très bien qu'elles ne ressemblent pas à Miss Jamaica, mais qu'importe! Au contraire, dans le dancehall vous voyez des femmes callipyges, avec leurs gros arrière-trains [big hips], leurs poitrines volumineuses et leurs tailles larges qui contrôlent l'espace et marquent une véritable présence ! Elles n'ont pas peur de se montrer ! Elles ne viennent pas pour se cacher, elles s'affichent et vous disent : «me voilà !». Donc il s'agit bien d'une prise de contrôle de l'espace et, par voie de conséquence, d'une prise de pouvoir!

18. À ce sujet, voir également : Zips W., «Tout n’est pas si noir dans cet Atlantique... noir. Du bandit au rebelle : transformations de la masculinité dans la musique reggae-dancehall ", Volume!, vol. 8, n² 2, 2011, pp. 123-159.

19. Marion Hall, a.k.a Lady Saw*, est la première femme deejay à s'être imposée - et ce dès les années 1990 - sur le terrain presque exclusivement masculin du slackness. Si bien que Carolyn Cooper voit en elle une pionnière qui, tout en parlant ouvertement de sa sexualité, n'a cessé d'affirmer le pouvoir des femmes sur leur corps et le désir qu'il peut susciter ; voir : Cooper C. , "Lady Saw Cuts Loose: Female Fertility Rituals in the Dancehall », Soundclash, op. cit., pp. 99-123. 

populaire dans la culture dancehall...

-C.C. : Absolument. C’est ce que je ne cesse pas de répéter depuis vingt ans tout en récoltant une foule de critiques, mais je continuerai 20 ! Parce que le féminisme n'est pas univoque. Au contraire, c'est un discours très complexe. Alors plutôt que d'en imposer une vision unique, il faut tenir compte de ses expressions racialisées et culturellement spécifiques! Je pense par exemple à Nanny qui, pour nous Jamaïcains, représente la quintessence du féminisme [voir encadré $n^{\circ} 2$ ]. À propos de Nanny, notre culture a conservé ce beau fragment mythique qui raconte qu'elle utilisait son arrière-train pour dévier les balles tirées par les soldats britanniques. Pour ma part, j’ai suggéré qu'il y a peut-être une connexion à déceler entre le puissant arrière-train de Nanny et la façon dont cette partie du corps féminin est utilisée dans le dancehall! Vous savez, l'arrière-train peut être une arme très puissante pour les femmes ! Ce saut imaginatif que je me suis amusée à faire m’a néanmoins conduite à l'idée de "marronnage érotique ». Je l'ai exprimée la première fois il y a un certain nombre d'années lors d'un colloque sur l'émancipation qui se tenait à l'Université des West Indies ; j'y ai proposé un papier qui traitait du dancehall comme d'un espace de rejet de la société plantocratique dont je voyais des survivances dans certaines catégories eurocentrées du discours normatif. Je laissais donc entendre que oui, il y a bien une forme de « culture du marronnage » dans l'érotisme du dancehall lorsqu'il rejette les conceptions occidentales de la respectabilité féminine.

\section{Nanny, le marronnage et son esprit}

Le 31 mars 1982, le gouvernement jamaïcain a reconnu en Nanny, reine des Marrons, la première et seule héroïne de la nation 21 ; une héroïne dont les fragments d'histoire doivent être recomposés puis lus au travers des rares pièces d'archive laissées par les colons anglais qui l'ont combattue. D'ascendance Ashanti, Nanny est censée avoir vu le jour à la fin du xvIle siècle dans l'actuel Ghana, avant d'être capturée et déportée vers la Jamaïque afin d'y être vendue comme esclave. Là, elle aurait appris l'existence de fugitifs regroupés dans les Blue Mountains; leur désignation par le terme «marrons »- ou marroons en anglais - est un dérivé de l'espagnol cimarrón, qui suggère l'idée de "vivre sur les cimes".

Avec quatre de ses frères d'infortune - Accompong, Cudjoe, Johnny et Quao - Nanny s'est échappée de la plantation où elle était détenue pour rejoindre les communautés de Marrons protégées par les montagnes et leur accès difficile. Sa connaissance de la spiritualité africaine - on la décrit souvent comme une Obeah woman (un terme qui renvoie aux sphères de la magie et de l'occulte) -, sa finesse d'esprit et son charisme l'ont peu à peu menée à la tête d'un groupe qui a fondé un camp retranché baptisé Nanny

20. Voir par exemple l'ensemble du dossier critique publié par le journal Small Axe (vol. 10, $\mathrm{n}^{\circ} 3$, 2006) suite à la parution de l'ouvrage Soundclash, op. cit.

21. Voir sa présentation officielle dans la liste des Jamaican National Heroes publiée sur le site du gouvernement : http://jis.gov.jm/heroes/nanny-of-the-maroons/ (consulté le 14/08/2016). 
Town. Ainsi son nom est-il peut être dérivé du mot ashanti Ni, qui signifie " mère » 22. Quoi qu'il en soit, les colons anglais n'ont pas tardé à livrer une véritable guerre aux Marrons dont ils ont attaqué les places fortes qu'ils appelaient Negroes towns (les "villes des Nègres »). Nanny Town, située près de l'actuelle Portland, apparaissait sur leurs cartes comme I'une des plus importantes. C'est lors de cette Première Guerre des Nègres marrons (First Marroon War, 1729-1739) que Nanny Town tombe en décembre 1734. D'aucuns prétendent que Nanny serait morte au cours de l'attaque ; d'autres attestent qu'elle a pris la fuite, puis refondé une communauté dans laquelle ses vieux jours se seraient écoulés en position de matriarche.

Parmi les nombreux textes écrits au sujet des Marrons de la Jamaïque, I'anthropologue et juriste autrichien Werner Zips a composé une ethnohistoire de ces figures archétypales de la résistance aux colonisateurs dont les sources tentent de contourner les biais d'une lecture par trop eurocentrée. Plutôt que de se fier aux seules archives de la répression constituées par les colons, Zips a convoqué son expérience des sociétés ouest-africaines combinée à un long travail de terrain en Jamaïque où il a recueilli de nombreux fragments de tradition orale qui évoquent à la fois I'histoire et I'héritage des Marrons. Le chercheur reconnaît ainsi dans le concept de Kromanti - forgé par les Marrons comme une expression de leur façon africaine de faire communauté - la racine et le ferment d'une culture de la résistance aux ramifications sociales, culturelles, artistiques et politiques 23 . Certains travaux de Stéphanie Melyon-Reinette se situent

dans le prolongement de cette idée en pro-

posant d'étudier les survivances du marronnage et de son esprit dans les arts expressifs de la Caraïbe ou, plus largement, de I'Atlantique noir ${ }^{24}$. Si la résistance est une femme, pour nombre de caribéens et de membres de la diaspora africaine, ses traits originels ne laissent pas de dessiner le visage et de prolonger le regard de Nanny.

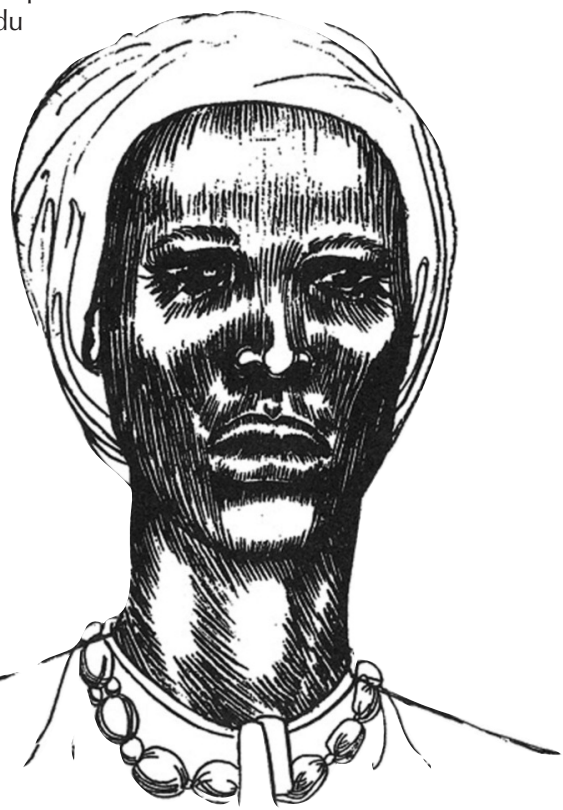

Nanny of the Maroons, portrait publié sur le site internet du gouvernement jamaïcain

22. Tuelon A., «Nanny - Maroon Chieftainess ", Caribbean Studies, vol. 19, n 4, 1973, p. 21.

23. Zips W., Nanny's Asafo Warriors. The Jamaican Maroons African Experience, Kingston \& Miami, Ian Randle Publishers, 2011.

24. Melyon-Reinette S. (ed.), Marronnage and Arts: Revolts in Bodies and Voices, New Castle, Cambridge Scholars Publishing, 2012. 
Prenons l'exemple du regard, et des corps exposés au regard. Pour le féminisme occidental - tout du moins certaines de ses versions - le regard des hommes est conçu comme quelque chose d'offensant : dans bien des situations, les femmes seraient à la fois les objets et les victimes du regard masculin. De telle sorte que toute l'idée d'être vue est considérée sous l'angle de l'appropriation : l'homme vous regarde comme s'il voulait instiller en vous l'idée de son contrôle, par le regard... Or, dans la culture dancehall le regard signifie tout le contraire! Dans ce contexte, les femmes s'habillent dans le but d'être regardées. Lorsque vous vous habillez comme elles le font et que vous montrez votre corps, le regard est sur vous - clairement !

Donc il s'agit bien d'une lecture différente : au lieu de concevoir les femmes comme autant d'objets dominés par le regard, il faut déceler leur pouvoir qui consiste à capter le regard et non pas à être captées par lui ! La raison pour laquelle on vous regarde étant précisément que vous constituez un puissant objet d'attention. Ce qui vous pousse à regarder cette femme plutôt qu'une autre est son pouvoir érotique ; son pouvoir de captation du regard, plutôt que le fait d'en être une simple victime. Au lieu de concevoir les femmes en tant qu'objets passifs du regard, on peut dès lors les considérer comme des sujets qui captent le regard, et le désir. C'est ainsi que je tente de relire toute cette politique du regard, laquelle peut s'avérer très différente d'une culture à l'autre! Donc je dis aux féministes occidentales : «Ne nous imposez pas votre regard, nous avons le nôtre et il signifie autre chose que ce qu'il vous arrive de croire ou de voir !»

-J.B. : J'aimerais à présent évoquer avec vous la haine des homosexuels, très présente dans le dancehall. Je me suis souvent demandé ce qu'indiquaient les affirmations, sans cesse répétées par certains deejays, d'une masculinité agressive qui se trouve être proférée par des subalternes issus des ghettos. Ces affirmations ne constituent-elles pas le signe d'un doute, doublé d'une peur concernant leur valeur d'homme dans une société jamaïcaine où ils ne sont pas respectés, pour ne pas dire simplement exclus?

-C.C. : Vous touchez à quelque chose que j'ai essayé de penser. Tout d'abord, il me semble qu'il faut dire que l'homophobie telle qu'on l'observe dans la société jamaïcaine vient tout droit de la Bible. Elle provient d'une lecture fondamentaliste de l'Ancien Testament, Lévitique, Chapitre 18. Je crois bien qu'il y est écrit que l'homosexualité est une abomination et ainsi de suite [\$22]. C'est une idéologie droite issue du fondamentalisme chrétien; ce n’est pas quelque chose de mauvais que les Jamaïcains auraient entièrement conçu par eux-mêmes. Ça vient de la Bible, et pour nombre de Jamaïcains la Bible reste un texte sacré. De sorte que vous ne pouvez pas convaincre des fondamentalistes chrétiens du fait que l'homosexualité ne constitue pas une abomination. C'est impossible! Peu importe la façon dont vous tenterez de leur 
expliquer qu'il n'y a aucune anormalité dans ces comportements... Non, pour eux c'est un péché ! Beaucoup vont même au-delà de cette idée du péché et pensent qu'il s'agit de quelque chose dont la société doit se débarrasser! Donc oui, la société jamaïcaine est bel et bien homophobe. Et les deejays ne cessent pas d'affirmer leur identité hautement pro-masculine. Ce qui n'est peut-être pas sans ambiguité ! Je vous rejoins donc sur l'idée que, sans doute, toute cette affirmation agressive de l'hétérosexualité cache une véritable incertitude quant à la sexualité de certains hommes qui s'affichent pourtant comme vigoureusement homophobes. C'est vraiment très compliqué ! Dans le même temps, j'essaie d'expliquer d'où provient l'homophobie en Jamaïque; et le fait qu'elle provienne de la Bible ne la rend pas si différente des positions homophobes qui sont affichées dans bien d'autres endroits. Donc je ne pense pas que ce soit une analyse honnête de la politique sexuelle globale que de présenter la Jamaïque comme l'endroit le plus homophobe au monde. En tant que critique de ma propre culture, je me dois de résister à la partialité d'une telle affirmation.

Qui plus est, $\mathrm{j}$ 'aimerais ajouter que je trouve très ironique l'attitude des Européens qui consiste à dire aux deejays jamaïcains : « ok, venez en Europe, mais évitez de nous servir vos textes homophobes parce que, sur notre marché, ça ne prend pas!». Dès lors que vous tournez les choses sous la forme d'un argument commercial, les deejays tendent à l'accepter d'autant plus facilement. Parce que oui, évidemment, ils veulent aussi faire de l'argent ! Mais ça ne s'arrête pas là : les Européens ne veulent pas simplement que vous renonciez à vous exprimer sur ces sujets lorsque vous venez en Europe ; ils veulent votre signature au bas d'une feuille qui stipule que vous ne direz rien en Jamaïque non plus! Ils exercent sur les deejays une police des textes à l'échelle globale ! Comprenez-moi bien : je ne défends en aucun cas les textes homophobes du point de vue d'un contenu dont je ne soutiens pas une seule idée. Mais je ne peux que m'élever contre la croisade morale que je viens de dénoncer - une de plus !

\section{Faya pon dem 25 , ou les enfers promis aux homosexuel(le)s}

Une note de l'organisation non gouvernementale Human Rights First publiée le 15 mai 2014 sous le titre "LGBT Issues in Jamaica » rappelle que I'homosexualité y est illégale depuis 1864 et qu'aucune modification de la loi n'est à l'ordre du jour. Entre 2009 et 2012, le principal groupe de défense LGBT (Lesbiennes, gays, bi et trans) de l'île - le Jamaican Forum for Lesbians, All-sexuals and Gays (J-Flag) - a recensé plus de deux cent trente et une affaires de discrimination et de violence impliquant des questions d'identité de genre et/ou d'orientation sexuelle. Toujours selon le J-Flag, plus de $80 \%$ des Jamaïcains accréditeraient l'opinion selon laquelle I'homosexualité est immorale et $75 \%$ d'entre eux s'opposeraient à toute abrogation des textes de loi existant à ce sujet 26 . Durant la campagne qui a précédé les élections générales de 2002 remportées par le People's National Party (i.e. les "démocrates »), le camp adverse du Jamaican Labour Party a 
choisi comme chant de ralliement un morceau dancehall explicitement homophobe : "Chi Chi Man »*, par T.O.K., qui appelle à brûler (métaphoriquement diront d'aucuns) les homosexuel(le)s. Comme l'explique Dona Hope, l'homophobie affichée dans le dancehall ne saurait dès lors être comprise comme une création ex nihilo; elle fait plutôt écho à un fonds homophobe aussi ancien qu'actif dans la culture jamaïcaine. Quant à la crudité de cet écho sur la scène dancehall, il s'accorderait selon l'auteure à la position subalterne de la plupart des deejays qui, issus des ghettos, verseraient dans une surenchère d'affirmation masculine visant à compenser la fragilité de leur position sociale au détriment de la figure-repoussoir de I'homosexuel - le batty man, ou chi chi man dans le vernaculaire local conçu comme l'homme inauthentique par excellence 27.

Nombre de deejays ayant atteint une stature internationale, depuis Shabba Ranks et Buju Banton (Mark Myrie) dans les années 1990 jusqu'à Vybz Kartel au cours de la dernière décennie, se sont ainsi attirés les foudres des activistes et autres défenseurs des droits de l'homme en Occident. En 2003, I'association LGBT britannique OutRage! a par exemple déposé plainte contre I'organisation des Music of Black Origin Awards 28, lesquels ont décerné des prix à Beenie Man (Anthony Davis), Bounty Killer (Rodney Price) et Elephant Man ( $\mathrm{O}^{\prime}$ Neil Bryan) - trois deejays aussi célèbres que connus pour leurs diatribes homophobes. Diffusé par Buju Banton en 1992, le morceau "Boom By-By »* est considéré comme l'acte fondateur de cette controverse qui a valu aux deejays incriminés l'annulation de nombreux concerts en Europe.

En revanche, dans les ghettos jamaïcains de telles attaques contre les stars du dancehall sont le plus souvent perçues comme autant de menées perverses orchestrées par Babylone (i.e. les institutions qui portent les valeurs de l'Occident postcolonial) et ses lobbys mondialisés pour affaiblir la culture ainsi que le style de vie de ceux qui ont fait le choix de s'y opposer. Un deejay comme Buju Banton, lequel a refusé tout compromis en s'arcboutant sur ce qu'il considère comme les principes inaliénables d'une morale inspirée du rastafarisme - une attitude qu'il scande dans le morceau "Complaint » (1995)*, où il moque les plaintes des Occidentaux -, est ainsi conçu par les plus pauvres tel un authentique résistant qui porte haut la fierté et les valeurs des sufferers ${ }^{29}$. Carolyn Cooper a forgé le concept de "border clash 30 "pour désigner ces affrontements (clashes) qui se déroulent dans des zones de conflits où les économies morales s'opposent aux frontières (borders) des mondes : ceux de la religion - ou certaines de ses interprétations - et de la sécularité, ceux du Nord et du Sud globalisés, ou ceux des sociétés instituées et des ghettos qui en constituent les marges.

25. Littéralement, «le feu sur eux » : interjection fréquemment employée dans le dread talk - et donc dans le dancehall - pour appeler à la punition des « corrompus ».

26. http://www.humanrightsfirst.org/resource/lgbt-issues-jamaica (consulté le 14/08/2016).

27. Hope D., "Passa Passa: Interrogating Cultural Hybridity in Jamaican Dancehall », Small Axe, $\mathrm{n}^{\circ}$ 21, 2006, pp. 132-133. De la même auteure, voir également : Man Vibes. Masculinities in Jamaican Dancehall, Kingston \& Miami, Ian Randle Publishers, 2010.

28. Il s'agit d'une cérémonie annuelle créé au Royaume-Uni en 1996 afin de saluer les apports des artistes qui contribuent aux «musiques noires».

29. En 2009, Buju Banton a toutefois été arrêté à Miami par la Drug Enforcement Administration (la brigade des stupéfiants) en possession de cinq kilogrammes de cocaïne ainsi que d'armes à feu. Suite à quoi un juge de la cour de Floride l'a condamné en 2011 à dix ans de réclusion ferme. Ses demandes d'extradition vers la Jamaïque ont jusqu'alors été refusées.

30. Cooper C. et Gutzmore C, «Border Clash. Sites of Contestation ", Soundclash, op. cit., pp. 35-72. 
-J.B. : "Résistance " apparaît comme un mot-clé dans les textes "conscients", depuis le reggae des commencements jusqu'à l'actualité du dancehall dit "culturel». Que pensez-vous d'un tel concept et comment l'articulez-vous à la musique ainsi qu'à la culture populaire jamaïcaine?

-C.C. : Je dirais que le concept de résistance est très complexe. Mais je crois que le premier sens que je lui attribue est inspiré d'un morceau de Bob Marley où il parle de la rythmique du reggae et de la sensation que lui procurent ses percussions alors que son cœur bat avec elles à l'unisson. Les rythmes vibrent alors comme la pulsation d'une résistance contre le «système» 31 . Je me sens en phase avec cette idée du reggae : le rythme, la musique et les textes comme un langage de résistance contre le « système »... Dans la culture jamaïcaine et dans le mouvement Rastafari, le «système » est appelé Babylone, i.e. tout ce nexus composé de politique, d'éducation et de religion : toutes ces institutions eurocentriques qui ont été imposées aux Noirs et ont véhiculé leurs normes morales, leurs appareils de pouvoir intellectuel, leurs règles de gouvernement, etc. Ce que dit Marley, c'est que le reggae entre en contradiction avec tout ce corpus d'idées, avec toute cette idéologie! De sorte que la résistance apparaît comme une forme d'engagement critique vis-à-vis de tous ces discours qui proviennent de l'extérieur et constituent les leviers de l'oppression. Pour certains d'entre nous, notre manière de réagir à la soi-disant culture «dominante » est dès lors pour le moins prudente; notre première disposition est au scepticisme : à la résistance, et pas à la simple soumission. Donc nous restons debout et refusons de mettre un genou à terre. Une fois encore, c'est une forme de marronnage. C'est une attitude oppositionnelle qui consiste à dire : « je dois voir les tenants et les aboutissants de toutes ces choses avant de consentir à les accepter ». D'ailleurs, l'étymologie latine du mot « résistance » renvoie à l'idée de «se retirer », «ne plus avancer » et «tenir sa position »; ce qui implique de ne rien accepter aveuglément. Il s'agit d'une forme de distance intellectuelle, ou de désengagement conscient à l'égard d'une certaine idéologie que l'on vous impose. C'est comme ça que je vois la chose : la résistance comme une attitude fondamentale tendant vers le scepticisme de principe. Cette idée m'a bien des fois guidée dans mon travail comme dans ma vie!

31. Il s'agit du morceau « One Drop »* publié en 1979 sur l'album Survival; entre autres choses, les paroles disent : "So feel this drum beat [Alors ressens la percussion]/As it beats within [Alors qu'elle bat à l'intérieur]/Playing a rhythm resisting against the system [Jouant ce rythme qui résiste au système] ». 


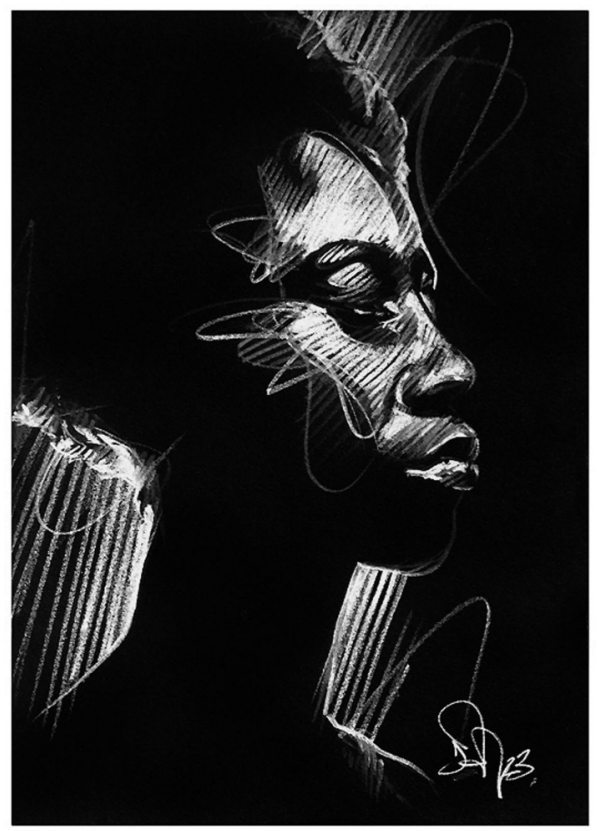

Make Sure, 2015 (c) Dan23
Made in Jamaica : regards sur l'entre-deux

La discussion avec Carolyn Cooper s'est poursuivie bien audelà des limites de ce dossier. J'ai donc dû faire des choix pour restituer l'essentiel - ou ce que j'ai tenu pour tel - de ce regard porté par une intellectuelle jamaïcaine à l'entre-deux, voire aux confluences de la littérature dont elle est une spécialiste et de l'oraliture des deejays qui portent la voix d'une scène dancehall à laquelle nombre de critiques seraient tentés de dénier la qualité

d'art, fût-il populaire. C'est pourtant à l'intersection du dit et de l'écrit - ou de l'oral et du scribal, pour reprendre ses termes - que toute l'œuvre de Carolyn Cooper a été composée comme une tentative d'analyse dialogique de sa propre culture, où il s'agit moins de porter un regard en surplomb que d'entendre toutes les voix qui en composent l'expression. Si bien que l'analyse culturelle se conçoit dès lors comme un intertexte offrant une multiplicité de points de vue et de lectures des situations. Exposer celles que les deejays donnent des ghettos jamaïcains ne signifie pas accréditer leurs opinions, justifier ou encore excuser leurs violences verbales et leurs excès. Montrer ne saurait être l'équivalent d'adhérer. C'est faire apparaître la vision interne d'un monde ; lui emprunter ses mots et parfois les traduire de sorte à ce qu'ils puissent être lus du dehors sans pour autant tronquer leur expression du dedans. Cet entre-deux constitue le défi et la position de nombre d'analystes culturels, qui sont peut-être avant tout des « auteurs en traduction».

Quant aux codes du dancehall traduits par Carolyn Cooper, eux aussi montrent un perpétuel entre-deux incarné par les deejays dont les mots ne cessent de balancer entre culture et slackness, ou extrême violence et conscience aigüe de l'oppression. Les rastas expliquent cette manière janusienne de vivre dos à dos avec soi-même comme la résultante du schisme interne que porteraient en eux tous les Noirs héritiers de l'esclavage et de sa Babylone plantocratique dont le système de domination a ouvert une insondable brèche dans leur moi profond ; depuis, la haine de soi et des siens inculquée par les anciens maîtres continuerait d'infecter le quotidien des ex-esclaves dont le métal des 
chaînes a été remodelé en armes à feu. Voilà ce que dit par exemple Neville Livingston, plus connu sous le nom de Bunny Wailer (dernier survivant du trio qu'il constituait avec Bob Marley et Peter Tosh), dans une séquence très forte du film Made in Jamaica* - réalisé par le français Jérôme Laperrousaz et sorti sur les écrans en 2007. Ce remarquable documentaire - entièrement soustitré en français, si bien qu'il permet un accès aux textes des chanteurs et autres deejays - présente le récit d'une scène musicale jamaïcaine où les rythmiques organiques du reggae roots, et l'âpreté de ses critiques sociales, côtoient les pulsations digitales d'un dancehall dont les ondes traversent les corps dans le même temps qu'elles restituent les échos du sexe, de la violence et de l'argent pour lesquels les sufferers ne laissent pas de s'entretuer. Aussi la narration filmée débute-t-elle par le meurtre en janvier 2005 de Gerald "Bogle" Levy, danseur emblématique du Black Roses Crew (un groupe de rue qui a posé son empreinte sur l'histoire du dancehall). Made in Jamaica reste dès lors comme hanté par le fantôme de Bogle, a.k.a «Mr. Wacky » ("Mr. Déjanté »)*, et la présence d'une violence marquée par son absence. Nombre de deejays dont il a été question au cours de l'entretien avec Carolyn Cooper apparaissent dans le film, depuis Lady Saw - qui a délaissé le slackness pour une conversion au christianisme évangélique prononcée le 14 décembre 2015 - jusqu’à Vybz Kartel (dont la peau était encore noire et vierge de tatouages). Tandis qu'il interprète "Emergency », une charge violente contre le gouvernement et les partis politiques dénoncés pour l'importation des armes à feu distribuées dans les ghettos, Kartel s'entoure de femmes à demi-nues qui s'exhibent, ondulent et miment des coïts sur fond de texte « conscient »; le schisme est bien là, qui traverse les corps, la culture et ses conflits... 